\section{B A Institute of \\ yk Business Administration \\ 六下 \\ Karachi \\ Leadership and Ideas for Tomorrow}

Business Review

Volume 11 Issue 1 January-June 2016

$1-1-2016$

\title{
The prevalent and persistent virtues of autocratic leadership in the corporate sector: An analysis
}

Nadya Chishty-Mujahid

Institute of Business Administration, Karachi, Pakistan

Follow this and additional works at: https://ir.iba.edu.pk/businessreview

\section{(c) (1)}

This work is licensed under a Creative Commons Attribution 4.0 International License.

\section{Recommended Citation}

Chishty-Mujahid, N. (2016). The prevalent and persistent virtues of autocratic leadership in the corporate sector: An analysis. Business Review, 11(1), 62-68. Retrieved from https://doi.org/10.54784/ 1990-6587.1078 


\title{
ARTICLE
}

\section{The Prevalent and Persistent Virtues of Autocratic Leadership in the Corporate Sector: An Analysis}

\author{
Nadya Chishty-Mujahid \\ The Institute of Business Administration, Karachi, Pakistan.
}

\begin{abstract}
Nineteenth-century critics ascertained that there were three major modes of leadership: autocratic, democratic, and laissez-faire. These had their origins in the background of leaders and the structures of power within which they were compelled to operate. Although autocratic leadership was a mode normally associated with the military, many corporate leaders of the early twentieth century (tycoons and company heads alike) were seen to employ this form of governance to varying degrees of effect. According to Simon Restubog, "historical observation suggests that as countries moved from nomadic hunting and gathering to settling in towns and producing food, environmental complexity was reduced and a more directive leadership emerged" (p. 113). While it has now become academically somewhat unfashionable to dwell on the virtues of directive and autocratic modes of governance, this article will demonstrate that within the major corporate sectors of today's business world, several diverse modes of leadership continue to retain a legitimate and strong kernel of autocracy. In his text titled Corporate Leadership, the Indian business academic Manoj Bhatt pays homage to the concept of autocratic leadership, and states categorically that "autocratic management has been successful as it provides strong motivation to the manager, [and permits] quick decision making" (p. 10). The following theories and assumptions will draw on research that reflects the varying roles played by factors such as directive leadership and even corporate social responsibility in shaping autocratic leadership practices. Indeed, it can be persuasively argued that since autocracy is the mode that takes over in times of pressure and crisis, it remains the most pervasive leadership practice for highly competitive business arenas. As with most socially dynamic disciplines, it becomes notoriously difficult to discuss terms such as "leadership" in a vacuum, especially since such concepts are infused with the weight of ever-changing management issues, institutional histories, and corporate practices.
\end{abstract}

Moreover, one consistently needs to keep in mind that leadership varies substantially across not just terrains of time, but actual geographical areas, i.e. the type of leadership that may have been acceptable during the British Raj in India cannot be applied to the day-to-day running of Google. While this may appear to be a valid point stemming from common sense, it does not detract from the fact that the study of leadership practice and leadership theory is a vital aspect of the comprehension and appreciation of how bosses control organizations. Michael Feiner who served extensively as the Chief People Officer of PepsiCola worldwide has recently written a book adroitly titled The Feiner Points of Leadership (a pun on his name), where he comes up with fifty corporate principles based on his experience. Feiner often underscores what he perceives to be the differences between being a leader and being a manager, but regardless of the subtle nuances of such contrasts, he states bluntly that: "By far the most common complaints in organizational life-from new managers, from seasoned executives, and from everyone else in between-concern working for bad bosses. The frustrations of working for a bad boss figure prominently in the complaints that I hear from the subordinates of my consulting clients, and in the reasons my MBA students give for returning to school, just as they did in the lives of many people who sought my counsel at Pepsi" (p. 73). In many cases strong-willed subordinates react to, and sometimes rebel against, autocratic and authoritative bosses; however, it might be fair-mindedly added that 
those are the ones who generally obtain results while less firm 'leaders' often prove to be bad bosses because they are simply not moving the work along.

As I noted earlier, over the course of the past century, numerous styles and modes of leadership have been identified and analyzed. From a corporate and management perspective, these generally fall into three main categories - autocratic, democratic and laissez-faire (which roughly translates from French into "hands off"). Autocratic leadership has been diversely but cohesively defined as "self-centered leadership and unilateral decision-making" or "domineering, egoistic [and] non-egalitarian" in nature (Restubog, p. 114). Jan Muczyk and Bernard Reimann stipulate that: "Autocratic leaders take the position that they are paid to make key decisions and the subordinates are compensated for executing those decisions. Thus subordinates are not involved in decision making under pure autocratic leadership" (p. 303). Democratic leadership more obviously factors the input of subordinates into decision-making, and laissez-faire leaders virtually never intervene in sorting out matters until they come to a crisis, in which case many of them are compelled to adopt a temporarily autocratic mode in order to solve problems. In competitive and pressured business sectors leadership may change from generation to generation. For instance, Henry Ford was a far more authoritative and autocratic leader than his successors: the latter had little choice but to relax the formerly autocratic policies of the founder's company partly due to greater international outreach and competition faced by Ford Motors. Nevertheless, this does not automatically equate with a glib truism that democratic leadership (whether it be corporate or gubernatorial) is preferable to autocratic. While commenting on the general nature of comparative governance Peter Burnell shrewdly argues that "claims about the absolute appeal of democracy and reference to widespread recognition of the imperative to clothe claims to political authority in language reminiscent of democracy, however bogus or strained, should not lead us to ignore the alternatives that continue to bestow some stability on autocratic regimes" (p. 548). Reinforcing Burnell's realistic assumption is the point that "unbridled enthusiasm for democracy and individual autonomy that pervades the very fiber of our society seems to have blinded many scholars and practitioners to the fact that few organizations can really achieve this ideal state in the workplace" (Muczyk and Reimann p. 309). Playing devil's advocate though, one can intrepidly assert that democracy may stem from a very valid sense of human idealism, and more Machiavellian democratic leaders may cultivate an illusion of autonomy within their subordinates. However, there is no arguing that the workplace, especially the corporate workplace is all too often bound by professional strictures and conventions that conflict with idealism to the point where the quality of work, mission, and inherent values of a business may become compromised - an utterly undesirable, and often financially detrimental, state of affairs.

In an interesting study carried out as far back as 1965 (but which is still relevant today), James Mullen conducted surveys of the contrastive management and leadership practices of three different division managers (A, B, and C) in a top US insurance company. Instead of labeling them autocratic, democratic and laissez-faire however, he chooses the terms "authoritarian, permissive and recessive." Within the precincts of the article although Mullen does not define this change of term as emerging from any specific motivation, it is significant that Mullen's choice of words implicitly, but unmistakably, shifts the linguistic weight of these terms from the realm of governance to that of business, i.e. from the generally gubernatorial to the corporate. In aggregate he did not perceive major differences in output and efficiency between the three managers, but insofar as how they were regarded by senior management his surmise is very telling. He notes: "The three superiors-a regional vice president and two deputy vice presidents - clearly and unequivocally stated their preference for Manager C, the authoritarian leader" over and above Manager A (the permissive leader) 
and Manager B (the recessive leader) which may have been largely due to the fact that "despite a higher degree of acceptance of his methods of leadership and better morale within his division, the permissive manager was unable to achieve a higher level of performance than the authoritarian manager (Mullen, p. 115, 120). It is entirely possible that the corporate modes and practices of the insurance company's authoritarian manager were perfectly in keeping with those of his superiors, which may have accounted for their marked preference for him over their other two subordinates. Given that the performance output of the authoritarian manager was not adversely affected by his lack of popularity amongst several of his own subordinates, Division Manager C stood in a better position to be promoted to the level of senior management in the future. Indeed, that may have been the tacit message that was being sent out by the regional vice-president of the company. Peter Burnell claims that "autocracies or hard authoritarian regimes vary in how they go about "systems maintenance"" but while senior management may not have been concerned much with the diverse modes of leadership at the division-manager level in Mullen's study as long as 'systems were being maintained,' operating at more senior leadership in the company would most certainly have veered strongly towards the autocratic/authoritarian (p. 561).

It is worth quoting James Mullen's description of Division Manager C in full, especially since it succinctly incorporates the gist of autocratic leadership practice: "[He was] an authoritarian, hard-driving leader. He had a highly energetic pattern and demonstrated a great deal of self-confidence. He was something of a perfectionist and tended to enforce company policies and regulations rather rigorously. He habitually exerted rather close supervision of his subordinates and tended to identify primarily with the goals of his superiors" (p. 109). Not only was this division manager ensuring that his subordinates would accomplish the requisite work in which they were expected to engage, he was also keeping the vision and mission of his superiors in mind. He was thus using his autocratic behavior to integrate his supervision with his immediate bosses' needs as well as the needs of the regional vice-president. In short, insofar as corporate functionality was concerned he was maintaining a functional and consistent chain-of-command. What is most admirable about Division Manager C's autocratic approach is that he did not simply wait to be promoted in order to behave like a true leader-he effected and executed at middle management level a style of leadership that would most definitely have been required and appreciated in the more powerful echelons of senior management. In fact, based on Mullen's study it can be safely surmised that consistency and practice of autocratic leadership at the middle management level would enable him to be better suited than his recessive and democratic counterparts to handling senior-level problems and concerns.

Writing over twenty years later, in an article that dwells on the theory of "directive" aspects of leadership Muczyk and Reimann still maintain that "we must not lose sight of the fact that the bulk of our leaders are found in organizations that provide less than 'excellent' environments for the exercise of participative leadership" and that "examples abound of business organizations where senior managers have lost control over the actions of key subordinates" (p. 302, 306). This twofold concern indicates that in many cases even middle management may be called upon to display autocratic behavior, since losing control over one's subordinates may damage the mission, vision, and ultimately the performance of a highly competitive corporation. It is ostensibly ironic that these critics believe that the majority of leaders are found in arenas where subordinate participation does not appear to be actively encouraged, since exerting and maintaining control over the actions of key subordinates requires a fairly close level of participation. However, their agendum becomes clearer when one finds that they extensively examine the issue of directive leadership - a phenomenon that promotes the participative intervention of leaders in order to guide and 
teach subordinates and shape their actions and motivations. They define a directive-autocrat as someone who "suits situations that require quick action, with no time for extensive employee participation. [He or she] would also be effective in an organization or sub-unit with limited scope or size and with relatively unstructured tasks. ... The directive autocrat is particularly well-suited to lead new, inexperienced or under-qualified subordinates" (p. 304, emphasis mine). The key word and major qualifier in their assessment and definition is "extensive" since, while that does not preclude participation, it implies that autocratic leaders indubitably place a high value on their time and do not subscribe to the notion that subordinates should require much hand-holding. In spite of coming up with a set of very cogent arguments that ultimately help strengthen their case for directive leadership, it is a pity that Muczyk and Reimann do not refer to a study that was published by Arthur Jago five years prior to theirs since it underscores the important twin concepts of leader-initiation and leader-consideration that could have benefitted their own work when it comes to clarifying some of their theories.

Jago believes that "leader initiating structure contributes to the satisfaction of followers engaged in ambiguous (i.e., unstructured) tasks and contributes to the dissatisfaction of followers engaged in clear (i.e., structured) tasks," whereas "leader consideration will have its most positive effect on the satisfaction of followers engaged in clear (i.e., structured) tasks" (p. 325). Therefore, given Muczyk and Reimann's abovementioned point that directive autocrats achieve greater levels of success than other leaders in dealing with subordinates who are engaged in relatively unstructured tasks, one may enhance their theory by noting, per Jago's assessment, that if directive autocrats engage in a process of leader-initiation their followers experience greater levels of guidance and professional satisfaction. Leader-initiation does not have to be as extensive in terms of participation as leader-consideration, which may harmonize better with a more democratic approach, though not perhaps a laissez-faire one. However, it is safe to assume that given the rigorous time constraints under which company heads and major directors operate they would invariably demonstrate the former patterns within governance as opposed to the softer, latter ones. Below the level of company head, senior level management would also be best served by demonstrating a leader-initiative approach of governance and guidance, underscoring their role as directive-autocrats. While there is no hard and fast rule as to whether leader-initiative behavior is inherently gendered in nature, noted author and financial manager Suze Orman states: "We still live in a time that presents us with obstacles to overcome simply because of our gender" (p. 321). One may take a moment to comment on the issue of gender and autocratic leadership briefly at this point.

In his article on social power and administrative leadership, Sven Lundstedt notes: "There are certain stereotypes, often associated with both leadership and management that contribute ... respectability to authoritarian administration. Firmness of character and clarity of thought ... are often associated with autocratic types of leadership [and] references are also made to its association with masculinity" (p. 160). Obviously Lundstedt will not go as far as to opine that the female gender is incapable of firmness of character and clarity of thought, indeed the undeniable competence of top business leaders such as Carly Fiorina and Indira Nooyi would belie such a sentiment. Nevertheless, given the differences between the genders, Sheryl Sandberg, the Chief Operating Officer of Facebook who has worked very closely with Mark Zuckerberg claims that not only do women need to be more assertive in leadership roles, men in positions of prominence in the corporate sector should actively encourage them to be more assertive. She anecdotally notes: "When a woman sits on the side of a room, a man needs to be able to wave her over to the table and explain why so she will know to sit at the table the next time. Ken Chenault, CEO of American Express, is a leader on this front. Ken 
openly acknowledges that in meetings, both men and women are more likely to interrupt a woman and give credit to a man for an idea first proposed by a woman. When he witnesses either of these behaviors, he stops the meeting to point it out. Coming from the top this really makes employees think twice" (Sandberg, p. 150). While Sandberg's point may be welltaken, based on this excerpt all Chenault appears to have done is simply take a quick, nonextensive directive-autocratic approach to including women's comments and ideas in corporate and executive meetings. He has been fair-minded but not unduly interventionist.

Chenault's being African-American and Indira Nooyi's being Indian would, given that they are both non-white, provide a further socio-political angle to this matter, but that does not change the autocratic authority that either of them possesses and is necessarily able to wield, and of which Sandberg brings forth an implicit example. Neither PepsiCola nor American Express can be defined by any stretch of the imagination as non-profit organizations where perhaps greater leader-consideration might need to apply. Hence, in the example cited above, Chenault was operating from a leader-initiative perspective. He was articulating a point of corporate social responsibility. Angus-Leppan, Metcalf and Benn claim that "a sense of duty [is] found to link most strongly with the perception of ethical leadership. This type of leadership [is] most prominent in non-profit organizations" (p. 193). These critics engaged in an important study of corporate social responsibility (CSR) whereby they highlighted, based on their corporate data, that "in the more hierarchical organization explicit CSR will be linked with autocratic leadership" whereas implicit CSR can be affiliated with less autocratic leadership (p. 209). This makes sense, especially given that autocratic leaders represent the visible face of their respective companies, hence explicit activities such as media-involvement in promoting the socially responsible aspects of their companies fall particularly under their domain.

Vocabulary such as 'explicit, directive, authoritarian, initiative, and autocratic' has indeed traditionally been associated with masculinity. One may further extend this argument and assume that such vocabulary can also be associated with practicality; hence Lundstedt's original statement above contains a kernel of indisputable truth. Moreover, the less practical and more idealistic fringe elements of leadership would not normally fall under the bracket of the vocabulary I have noted above or be directly related to governance practices best reflected by such labels. G. Bassiry surmises that: "While it might be that the essential socializational ingredient that promotes ethically and socially enlightened business leadership lies in the deeper realm of human beliefs and values, awareness and knowledge exposure are certainly pivotal components of behavior change" (p. 804). One need not get into a futile argument at this point as to whether autocratic leaders are ethical or not, but Bassiry's point regarding knowledge exposure certainly merits some additional consideration.

Autocratic leaders are expected to be fully-informed decision makers, and are expected to possess a condensed version of the salient features of matters in order to decide on them with relative rapidity and then have their decisions implemented at an equally smooth pace. Abhishek, Bartol, and Locke extensively discuss the concept of knowledge sharing. They regard knowledge-sharing and team-efficacy within corporations as vital mediating factors between leadership and team performance. Their study is particularly important as it implicitly views leadership as a dynamic process as opposed to a fixed set of traits. The critics claim that they "consider the role of knowledge sharing as a team process, and team efficacy as an emergent state in the empowering leadership-performance relationship....Knowledge sharing is an important component of knowledge management, as it helps in codifying the repository of available knowledge in an organization and increasing it over time." (pp. 1239-1240). In the interests of secrecy and confidentiality many military and corporate autocratic leaders (especially in for-profit organizations) are often found to engage 
in what are at best semi-transparent practices. However, no man is an island, and autocratic leadership does not necessarily preclude the possibility of delegation and knowledge-sharing. Indeed, many autocratic and even military leaders know how and when to delegate some aspects of authority - this is why in structural terms major businesses can come across as hierarchical as the armed forces. Abhishek, et.al speculate that were a leader to share his or her knowledge with his or her subordinate teams and be receptive to receiving knowledge back from those team members, such exchange if conducted through appropriate professional channels would prove beneficial for the corporation. Moreover, as the critics note, the knowledge would build on itself for the betterment of the institution concerned. By drawing attention to leadership as a process, this study goes a step beyond Jago, Muczyk and Reimann's respective articles where purposeful directive behavior and initiative-taking are primarily traits that fall under the domain of autocratic leadership - thus they are part of processes, but not processes in and of themselves.

Finally, one should devote some attention to underscoring changing trends in developing definitions of leadership since these trends necessarily tie in with the question of leadership as a process rather than a set of traits. James McElroy comments that "personal traits, while once a dominant paradigm for studying leadership have long since given way to studies of leader behavior and situational approaches to leadership" (p. 90). He is correct in assuming that a leader should at least partially adapt his or her style to suit the occasion and the situation otherwise he or she risks not finding a solution to the problem at hand. It is naïve to operate from the assumption that large, highly competitive corporate businesses (or even small businesses) do not face a plethora of problems every day. Herein, however, we come almost full circle to the question posited at the beginning of this article-i.e. that which revolves around why autocratic leaders are generally regarded as the best crisis-managers and problem solvers. Before commenting further on that we can appreciate a more nuanced definition of this change in noting how leadership is now viewed academically by focusing on the recent words of eminent Indian businessman, R. Gopalakrishnan; the Director of Tata Sons in Mumbai writes: "Traditionally leadership has been considered to be either an inheritance for those born in powerful families or a born trait among some who went on to acquire power. However, through the past century, as management became a knowledge discipline, there have been significant changes in the way people think about leadership. Increasingly, leadership is being looked at more as a competence and less as a trait. While individual characteristics - intelligence, courage, charm, etc.—remain vital to leadership, the situational and organizational factors now play a greater role in performing the leadership function" (p. viii, emphasis mine). Gopalakrishnan negotiates a middle ground between process and trait by claiming that leadership rests on both inherent and acquired competence; on a very fundamental level it may be accurately viewed as an acquired skill that is enhanced and expanded by experience, and occasionally by luck. Whether one specifically and consciously decides to develop autocratic competence (regardless of whether one is thus inclined by nature or background) becomes a matter of personal choice. In the case of Director C in Mullen's study, even those subordinates who regarded him unfavorably should have ascertained that since senior management had seen him in a positive light, their own approach to work would benefit from adapting to autocratic attitudes, rather than expecting their leader to adapt to them.

Muczyk, Reimann and Jago all accurately perceived that autocrats deal best with structured approaches to problems, but while speaking about situational leadership Michael Armstrong and Tina Stephens are even more explicit in noting that "a task-oriented approach (autocratic, controlling, transactional) may be best in emergency or crisis situations or when the leader has power, formal backing, and a relatively well-structured task" (p. 14). Hence, 
autocrats acclimate themselves to respecting structure, because at the executive level greater structure and organization invariably simplifies problem-solving. This idea is of special significance because Armstrong and Stephens underscore this, not in an academic article for a few specialists, but in a handbook that several students can be expected to access and utilize. One may add that one of the prime goals of directive autocrats is to shape the behavior of subordinates to the point where they provide greater structure and clarity to tasks, thereby minimizing crises, chaos and problems, and leaving the handling of inevitable serious business crises to executive teams that can also depend on an autocratic approach, albeit a more senior one, to solve them efficiently and comprehensively. Therefore, to conclude I will end with a self-explanatory quote from the devious, but successful, Renaissance man Niccolo Machiavelli who encapsulated a sentiment close to the hearts of virtually all autocratic leaders: "A wise prince should establish himself on that which is in his own control and not in that of others" (The Prince, Chapter XVII).

\section{References}

Abhishek, S., K. Bartol, and E. Locke. (2006). Empowering Leadership in Management Teams: Effects on Knowledge Sharing, Efficacy and Performance. The Academy of Management Journal, 49(6) ,1239-1251.

Armstrong, Michael and Tina Stephens. (2005). A Handbook of Management and

Leadership: A Guide to Managing For Results, London: Kogan Page,.

Angus-Leppan, T., L Metcalf, and S. Benn. (2010). Leadership Styles and CSR Practice: An Examination of Sensemaking, Institutional Drivers and CSR Leadership. Journal of Business Ethics, 93(2), 189-213.

Bassiry, G. R. (1990). Ethics, Education, and Corporate Leadership. Journal of Business Ethics, 9(10), 799-805.

Bhatt, Manoj. (2012). Corporate Leadership, New Delhi: Random House.

Burnell, Peter. (2006). Autocratic Opening to Democracy: Why Legitimacy Matters. Third World Quarterly, 27(4), 545-562.

Feiner, Michael. (2004). The Feiner Points of Leadership, New York: Warner Books.

Gopalakrishnan. R. (2012). Foreword to Leaders on Leadership: Insights from Corporate India, New Delhi: SAGE.

Jago, Arthur. (1982). Leadership: Perspectives in Theory and Research. Management Science, 28(3) 315-336.

McElroy, James. (1991). Attribution Theory Applied To Leadership: Lessons From Presidential Politics. Journal of Managerial Issues, 3(1), 90-106.

Muczyk, Jan and Bernard Reimann. (1987). The Case for Directive Leadership. The Academy of Management Executive (1987-1989), 1(4), 301-311.

Mullen, James. (1965). Differential Leadership Modes and Productivity in a Large Organization. The Academy of Management Journal, 8(2), 107-126.

Restubog, Simon Lloyd. (2006). Can Weather and Wealth Make Bosses Self-Centered? Academy of Management Perspectives, 20(3), 113-115.

Lundstedt, Sven. (1965). Administrative Leadership and the Use of Social Power. Public Administration Review, 25(2), 156-160.

Orman, Suze. (2010). Women and Money, New York: Spiegel and Grau.

Sandberg, Sheryl. (2013). Lean in For Graduates, New York: Random House. 